Arq. Bras. Med. Vet. Zootec., v.70, n.3, p.689-698, 2018

\title{
Efeito do tipo de alimentação de cães saudáveis sobre análises clínicas e aspectos comportamentais
}

\author{
[Effect of the diet of healthy dogs on clinical analysis and behavioral aspects] \\ I.C.S. Araújo ${ }^{1}$, A.P. Furtado ${ }^{2}$, G.C.P. Araújo ${ }^{3}$, C.G. Rocha ${ }^{3}$ \\ ${ }^{1}$ Escola de Veterinária - UFMG - Belo Horizonte, MG \\ ${ }^{2}$ Aluna de pós-graduação - Faculdade de Agronomia e Veterinária - UnB - Brasília, DF \\ ${ }^{3}$ Aluna de graduação - Faculdade de Ciências da Saúde de Unaí - Unaí, MG
}

\begin{abstract}
RESUMO
Objetivou-se estudar o efeito da alimentação caseira, da ração comercial a granel e da ração comercial fechada para cães adultos sobre análises clínicas e aspectos comportamentais de ingestão das dietas. O delineamento experimental foi inteiramente ao acaso, com três tratamentos, sendo o tratamento 1 constituído de dieta caseira, o tratamento 2 por ração a granel tipo premium, e o tratamento 3 por ração comercial fechada do tipo premium. Foram utilizados três cães em cada um dos tratamentos, totalizando nove animais. As variáveis analisadas foram: teste de glicemia, odor fecal, escore fecal, volume fecal, análise química da urina ( $\mathrm{pH}$ urinário, presença de proteína, sangue, corpos cetônicos, bilirrubina e glicose), avaliação visual do pelo e consumo voluntário da dieta. Os cães submetidos à dieta caseira apresentaram menor resultado de glicemia sanguínea $(83,90)$. A urina apresentou $\mathrm{pH}$ mais alcalino para cães que receberam a ração a granel $(8,06)$. Cães da dieta caseira apresentaram o mais alto escore para a qualidade do pelo. Houve um maior volume das fezes de cães que receberam a dieta de ração a granel. Cães que receberam a dieta de alimentação caseira ou a ração comercial fechada apresentaram um consumo total do alimento em menos de 10 minutos. A maioria dos resultados foi semelhante entre a dieta caseira e a ração fechada do tipo premium. A ração a granel apresentou os piores resultados.
\end{abstract}

Palavras-chave: alimentação caseira, canino doméstico, ração a granel, ração comercial

\begin{abstract}
The objective of this study was to study the effect of homemade feed, commercial feed in bulk, and closed commercial feed for adult dogs on clinical analysis and behavioral aspects of diet intake. The experimental design was completely randomized with three treatments: homemade diet, bulk premium type feed, and closed commercial feed of the premium type. Three dogs were observed in each of the treatments, totaling nine animals. The variables analyzed were: blood glycemia, fecal odor, fecal score, fecal volume, chemical urine analysis (urinary $\mathrm{pH}$, presence of protein, blood, ketone bodies, bilirubin and glucose), visual evaluation of hair and voluntary dietary intake. Dogs submitted to a home diet showed lower blood glucose results (83.90). Urine was more alkaline $\mathrm{pH}$ for dogs that received the bulk feed (8.06). Dogs from the homemade feed presented the highest score for hair quality. There was a greater volume of feces from dogs that received the diet of bulk feed. Dogs that received the diet of home feed or closed commercial feed showed a total consumption of food in less than ten minutes. Most of the results were similar between the homemade feed and the closed-type premium diet. The dogs bulk feed presented the worst results.
\end{abstract}

Keywords: homemade food, canine domestic, feed in bulk, commercial feed

Recebido em 2 de janeiro de 2017

Aceito em 28 de setembro de 2017

E-mail: italloconradovet@hotmail.com 


\section{INTRODUÇÃO}

A domesticação do cão iniciou no continente europeu há cerca de 18 mil anos e, desde então, a espécie tornou-se uma das mais bem adaptadas à convivência direta com o ser humano. Durante o processo de domesticação, os humanos selecionaram os cães mais dóceis e adaptáveis para servir como animais de trabalho (Thalmann et al., 2013). Assim, a associação direta dos cães ao ambiente do homem proporcionou diversas funções para os caninos domésticos, tais como: proteção, controle de roedores, caça e companheirismo.

De acordo com Tsuda et al. (1997), os cães domésticos que estão em contato direto com o homem são descendentes do lobo-cinzento holártico (Canis lupus), animal essencialmente carnívoro, entretanto, de acordo com Félix (2011), o hábito alimentar dos lobos é variável e eles têm o costume de ingerir carboidratos e fibras quando consomem o conteúdo gastrointestinal das presas, ainda frutas e partes de plantas, sendo classificados como animais carnívoros não estritos.

Os hábitos alimentares dos ancestrais têm sido levado em conta para a elaboração de rações para os cães. De acordo com Buff et al. (2014), a dieta dos cães modernos tem sido formulada para atender suas exigências nutricionais, com a inclusão de alimentos de origem vegetal e animal; ou seja, por meio do antropomorfismo, o homem tem transformado o cão em um animal onívoro, deixando este de ser carnívoro não estrito. Assim, nas últimas décadas, houve uma grande evolução na alimentação dos cães. Segundo Rocha (2008), nos anos 80 e 90, devido ao pequeno número de indústrias de rações, os proprietários forneciam restos de alimentos caseiros aos cães, entretanto, com a evolução do mercado, há hoje rações com diversas especificidades.

No contexto de mercado de rações, o Brasil é o segundo país do mundo em faturamento na área de alimentos para cães, ficando atrás somente dos Estados Unidos. No ano de 2014, entre janeiro e março, a produção na indústria pet food nacional ultrapassou 500 mil toneladas, sendo 470 mil toneladas de alimentos para cães (Mendes et al., 2014). Entretanto, no ano de 2015, o consumo de alimentos pelos animais de companhia no Brasil diminuiu cerca de $2 \%$ em razão do aumento da inflação e do desemprego, o que resultou em uma produção de 2,437 milhões de toneladas de ração, uma produção menor em comparação ao ano de 2014, quando se produziram 2,492 milhões de toneladas de ração (Zani, 2015).

Dada a preocupação dos proprietários com a qualidade dos alimentos que atendem as exigências nutricionais, bem como a escolha de alimentos ausentes de ingredientes artificiais, algumas indústrias de alimentos passaram a optar pela produção de alimentos naturais. Entretanto, é importante ressaltar a distinção entre uma dieta natural e uma dieta caseira. De acordo com Saad e França (2010), entende-se por dieta natural alimento ausente de processos químicos, conservantes artificiais e aditivos.

Segundo Morais (2015), a alimentação caseira também possui ingredientes de origem natural, porém são utilizados produtos industrializados (vitaminas, minerais e nutracêuticos) com o intuito de completar o alimento. A alimentação caseira tem como vantagens: a realização de dietas de acordo com a necessidade nutricional de cada animal e corretamente equilibrada, melhor palatabilidade, maior concentração de umidade, o que reduz problemas urinários, e diminuição da quantidade de substâncias tóxicas.

Os diferentes tipos de dietas que existem atualmente para cães influenciam diretamente em diversos fatores, como a saúde, o desempenho zootécnico e a reprodução. De acordo com França et al. (2011), as proteínas e os carboidratos nas dietas de cães interferem na palatabilidade, na digestibilidade e na qualidade das fezes, sendo os lipídeos a maior fonte de energia em comparação com as proteínas e os carboidratos e também o grupo nutricional que mais interfere na palatabilidade do alimento.

A qualidade dos alimentos para os animais de estimação vem sendo, a cada dia, melhorada, por isso é importante avaliar as dietas que são fornecidas, para a escolha da melhor opção, ou seja, a dieta que supre suas exigências nutricionais e que garante seu bem-estar. Diante do exposto, objetivou-se avaliar o efeito da alimentação caseira, da ração comercial fechada e da ração comercial a granel sobre a glicemia sanguínea, a análise química da urina, o odor, o 
escore e o volume fecal, a aparência do pelo e o consumo voluntário da dieta.

\section{MATERIAL E MÉTODOS}

O experimento foi aprovado pelo Comitê de Ética e Pesquisa com Animais da Faculdade de Ciências da Saúde de Unaí-MG. Foram selecionados nove cães machos, adultos e saudáveis, sem raça definida, de pequeno porte e na mesma média de peso $(6,3 \pm 0,8 \mathrm{~kg})$. Os cães foram distribuídos em delineamento inteiramente ao acaso, um em cada gaiola metabólica, e os tratamentos foram constituídos por três tipos diferentes de dietas. $\mathrm{O}$ tratamento 1 foi composto por uma dieta balanceada, utilizando-se alimentos naturais cozidos, e os tratamentos 2 e 3 utilizaram uma mesma ração comercial tipo premium. $\mathrm{O}$ tratamento 2 foi constituído de ração tipo premium a granel, com o saco de ração deixado aberto em ambiente de sala de alvenaria fechada, dotada de uma janela que era aberta no início da manhã (oito horas) e fechada no final da tarde (18h), e com exposição ao ambiente por um período de 30 dias consecutivos, simulando o que acontece em casas agropecuárias que comercializam ração a granel. O tratamento 3 foi composto de ração comercial fechada do tipo premium, sendo três animais em cada tratamento, totalizando três tratamentos com três repetições cada.

A pesquisa teve duração de 21 dias, em que, inicialmente, os cães passaram por um processo de adaptação de cinco dias. As análises foram, então, realizadas em dois tempos. Primeiramente, após esse período de adaptação, do sexto ao $10^{\mathrm{o}}$ dia, e nos cinco dias finais do experimento, do $17^{\mathrm{o}}$ ao $21^{\mathrm{o}}$ dia.

A dieta caseira foi formulada de acordo com NRC (Nutrient..., 2006) para estudo com cães adultos e ativos, sendo os ingredientes distribuídos conforme a seguir: $30 \%$ de carne (coxão mole bovino moído), 65\% de um mix de vegetais (batata doce (30\%); inhame (30\%); aboborinha verde (10\%); cenoura $(15 \%)$; chuchu $(15 \%)$ ) e 4,9\% de víscera animal (fígado bovino) e cloreto de sódio (sal comum iodado) $(0,1 \%)$. O preparo da dieta caseira foi feito da seguinte forma: a carne bovina foi cozida sem uso de óleo, com uma pitada de sal, e os legumes utilizados foram fatiados em pequenos cubos e cozidos por 25 minutos em água sem se adicionar sal; o fígado foi fatiado em pequenos cubos e salteado em frigideira sem adição de óleo. A dieta foi servida morna e com os ingredientes misturados. Foi realizada a análise bromatólogica da alimentação caseira, de acordo com Silva e Queiroz (2002). Primeiramente foram determinadas a umidade e a matéria seca, obtidas em estufa, a $105^{\circ} \mathrm{C}$, por 24 horas. Para a análise bromatológica, as amostras frescas foram secas em estufa a $55^{\circ} \mathrm{C}$ por 72 horas. Depois disso, as amostras foram moídas e seguiram para os procedimentos específicos. A proteína bruta (PB) foi determinada por meio da porcentagem de $\mathrm{N}$, pelo método de Kjedahl. A matéria mineral (MM) total foi determinada por queima total em mufla e pela diferença de pesagem inicial e final; a energia bruta (EB) foi obtida pela queima total das amostras, utilizando-se calorímetro adiabático PARR. Por fim, a determinação do teor de extrato etéreo (EE) das amostras foi feita por meio de aparelho de Goldfish. Na Tab. 1, estão descritos os níveis de garantia do rótulo da ração comercial e também estão apresentados os resultados da análise bromatológica na matéria seca da dieta caseira.

Ingredientes da ração comercial premium: farinha de vísceras de frango, milho integral moído, quirera de arroz, proteína isolada de suíno, gordura de frango, polpa de beterraba, farelo de arroz desengordurado, gordura suína, levedura seca de cervejaria, hidrolisado de frango, semente de linhaça, lisina, premix vitamínico (ácido fólico, ácido pantotênico, biotina, colina, niacina, vitamina A, vitamina B1, vitamina $\mathrm{B} 12$, vitamina $\mathrm{B} 2$, vitamina $\mathrm{B} 6$, vitamina $C$, vitamina $D 3$, vitamina $E$, vitamina $\mathrm{K} 3$ ), premix mineral transquelatado (cobre, ferro, iodo, manganês, selênio, zinco), cloreto de sódio, cloreto de potássio, parede celular de levedura, antioxidantes BHA e BHT.

A quantidade de dieta fornecida foi determinada de acordo com o peso de cada animal, sendo a ração a granel e a ração comercial fechada de 96 gramas por dia para cada cão. Na dieta caseira, o consumo do animal 1 foi 390 gramas, o animal 2 foi de 300 gramas e o animal 3 foi de 360 gramas por dia, sendo calculados $5 \%$ sobre o peso do animal. Dessa forma, cada dieta foi pesada de acordo com o consumo diário de cada animal. 
Tabela 1. Níveis de garantia da ração comercial fechada e análise bromatológica das dietas oferecidas aos cães (ração comercial fechada, econômica a granel e dieta caseira)

\begin{tabular}{ccccc} 
Composição da dieta & $\begin{array}{c}\text { Rótulo da ração } \\
\text { comercial }\end{array}$ & $\begin{array}{c}\text { Ração comercial } \\
\text { fechada }\end{array}$ & $\begin{array}{c}\text { Ração comercial } \\
\text { a granel }\end{array}$ & Dieta caseira \\
\hline Umidade $(\%)$ & 10,00 & 10,54 & 12,70 & 73,00 \\
Proteína bruta (\%) & 23,00 & 22,95 & 26,13 & 45,12 \\
Extrato etéreo (\%) & 12,00 & 14,00 & 13,50 & 38,40 \\
Matéria fibrosa (\%) & 3,00 & 2,91 & 2,88 & 2,89 \\
Matéria mineral (\%) & 7,50 & 7,50 & 12,00 & 7,04 \\
Energia bruta (kcal/kg) & 3.881 & 3.730 & 3.555 & 5.290 \\
\hline
\end{tabular}

As variáveis analisadas no experimento foram: teste de glicemia sanguínea do animal em jejum, análise das fezes por meio do odor fecal, do escore fecal e do volume fecal, análise química da urina (pH urinário, proteína, sangue, corpos cetônicos, bilirrubina e glicose), avaliação visual do pelo, consumo voluntário da dieta e acompanhamento do ganho de peso de cada cão. As análises de escore, volume e odor fecal, a análise química da urina e a pesagem dos cães foram realizadas antes do fornecimento das dietas, e somente a avaliação do pelo foi realizada após as refeições.

O teste de glicemia foi realizado uma vez ao dia, com o animal em jejum durante os períodos de análises, e as amostras de sangue foram colhidas da veia cefálica. Foi avaliado o odor fecal utilizando-se adaptação proposta por Aquino et al. (2012), que avaliaram as fezes por meio de uma amostra padrão, a saber, a dieta comercial fechada, mediante o uso de uma escala de valores de 0 a 4 (0 - amostra com odor extremamente pior que o do padrão; 1 - pior que o padrão; 2- igual ao padrão; 3- melhor que o padrão e 4- muito melhor que o padrão). No presente experimento, foi utilizada como amostra padrão a ração comercial fechada. A análise do odor fecal foi realizada sempre pelas mesmas duas pessoas durante o período experimental.

O escore fecal foi avaliado por meio do nível de consistência e do formato das fezes. Dessa forma, determinaram-se níveis de escore de 1 a 5 (1- fezes líquidas, diarreia; 2 - fezes macias, sem forma definida; 3 - fezes macias, bem formadas e úmidas; 4 - fezes duras, secas, firmes e bem formadas; 5 - fezes muito duras e ressecadas). Ainda, o volume fecal foi avaliado visualmente por meio da escala de 1 a 3 ( 1 - fezes pouco volumosas; 2 - fezes volumosas e 3 - fezes muito volumosas). A análise do escore fecal foi realizada sempre pelas mesmas duas pessoas durante o período experimental.

Para análise química da urina, a primeira urina da manhã foi colhida pelo método de micção natural, sendo analisados o $\mathrm{pH}$ e a presença de proteína, sangue, corpos cetônicos, bilirrubina e glicose. A análise foi realizada por meio de uma tira de reagente $\left(\right.$ Biocon $^{\circledR}$ ), que foi colocada dentro de uma placa de Petri contendo urina; após sua retirada, aguardou-se um minuto para se realizarem as análises de cada componente.

O pelo foi avaliado por três observações visuais, sendo considerados os aspectos de maciez, brilho e queda. Foi atribuída escala de 0 a 3, analisando-se o aspecto macio ou duro (0 - pelo duro; 1 - pelo pouco duro; 2 - pelo pouco macio e 3 - pelo macio), opaco ou brilhante (0 - pelo opaco; 1 - pelo pouco opaco; 2 - pelo pouco brilhante e 3 - pelo brilhante) e queda de pelo (0 - muita queda de pelo; 1 - pouca queda de pelo; 2 - ligeira queda de pelo; 3 - nenhuma queda de pelo). A análise do pelo foi realizada sempre pelas mesmas duas pessoas durante o período experimental.

O consumo voluntário da dieta foi avaliado pelo tempo de consumo das dietas, sendo analisado até 30 minutos, por meio da observação da quantidade total de vezes que os cães do grupo consumiram entre zero e 10 minutos, 11 e 20 minutos ou 21 e 30 minutos; quando passava de 30 minutos, a ração era retirada e descartada.

A análise estatística das variáveis estudadas foi realizada utilizando-se software $\mathrm{R}$ ( $\mathrm{R}$ Development Core Team, 2016) e adotou-se análise de variância (ANOVA), sendo as médias comparadas pelo teste de Tukey (5\%) para comparação das médias paramétricas e o teste de Kruskal-Wallis (5\%) para as análises não paramétricas. 


\section{RESULTADOS E DISCUSSÃO}

Os resultados da glicemia sanguínea dos cães em jejum submetidos a diferentes dietas, avaliados em dois períodos de cinco dias, estão representados na Tab. 2. O valor da glicemia da dieta caseira apresentou resultado menor em comparação às outras dietas $(\mathrm{P}<0,05)$. Não houve diferença entre a ração comercial a granel e a fechada.

Tabela 2. Glicemia sanguínea de cães em jejum submetidos a diferentes dietas, avaliados em dois períodos de cinco dias

\begin{tabular}{lccccc} 
& Dieta caseira & Ração a granel & Ração fechada & Valor de P & CV (\%) \\
\hline Glicemia & $83,90 \mathrm{~b}$ & $90,35 \mathrm{a}$ & $89,37 \mathrm{a}$ & $0,0421 *$ & 13,31 \\
\hline *Médias seguidas por letras diferentes são diferentes pelo teste de Tukey (5\%). & & & \\
CV - coeficiente de variação.
\end{tabular}

CV - coeficiente de variação.

A glicose sanguínea normal dos cães em jejum é de 70 a $110 \mathrm{mg} / \mathrm{dL}$ (Beltrame et al., 2015), portanto os valores de glicemia avaliados estão dentro da normalidade para todos os grupos estudados. Todavia, o grupo de cães alimentados com a dieta caseira apresentou menor resultado da glicemia em comparação aos grupos alimentados com as outras dietas. Esse resultado pode indicar uma alternativa para suporte terapêutico de cães que apresentam doenças como a Diabetes mellitus. Ainda, de acordo com Saad e França (2010), o excesso de carboidratos nas dietas eleva a glicemia sanguínea dos cães e pode propiciar doenças como obesidade, hiperinsulinemia e resistência à insulina. Dessa forma, a dieta caseira pode servir como prevenção para doenças desse tipo.

A dieta caseira utilizou como fonte de carboidratos a batata doce e o inhame, que, de acordo com Lamounier et al. (2010), possuem moderado índice glicêmico, isso é, eles controlam a glicemia chegando à corrente sanguínea gradativamente. Esses autores também relatam que o milho apresenta um alto índice glicêmico, sendo esse ingrediente presente na formulação da ração dos outros dois tratamentos.

Os cães que foram alimentados com a ração a granel apresentaram maior quantidade de proteínas na urina (Tab. 3), seguidos pelos cães alimentados com a ração comercial fechada e a dieta caseira $(\mathrm{P}<0,05)$. Para o valor do $\mathrm{pH}$ da urina dos cães, não houve diferença entre a dieta caseira e a ração comercial fechada $(\mathrm{P}>0,05)$, porém o resultado do $\mathrm{pH}$ da ração a granel foi maior $(\mathrm{P}<0,05)$ em comparação com as outras dietas.
A proteinúria é normal em pequenas quantidades, sendo o teste empregado sensível mais para albumina do que para globulina, e a presença dessa proteína na urina pode ser causada por doença renal, inflamação ou infecção do sistema urinário (Botelho et al., 2012). Dessa forma, confirma-se a hipótese de não existir uma associação específica da dieta com a proteína presente na urina dos cães.

Tabela 3. Análise química da urina de cães submetidos a diferentes dietas, avaliados em dois períodos de cinco dias

\begin{tabular}{cccccc}
\hline & Dieta caseira & Ração a granel & Ração fechada & Valor de P & CV $(\%)$ \\
\hline $\begin{array}{c}\text { Proteínas } \\
(\mathrm{mg} / \mathrm{dL})\end{array}$ & $40,83 \mathrm{~b}$ & $68,88 \mathrm{a}$ & $55,76 \mathrm{ab}$ & $0,0342 *$ & 12,10 \\
$\mathrm{pH}$ & $5,95 \mathrm{~b}$ & $8,06 \mathrm{a}$ & $6,10 \mathrm{~b}$ & $0,0120^{*}$ & 7,20 \\
\hline
\end{tabular}

*Médias seguidas por letras diferentes na mesma linha são diferentes pelo teste de Tukey (5\%).

$\mathrm{CV}$ - coeficiente de variação.

Segundo Ettinger e Feldman (2014), a dieta e o equilíbrio acidobásico influenciam no $\mathrm{pH}$ da urina em cães, sendo o valor normal de 5,0 a 7,5. De acordo com os mesmos autores, o pH urinário ácido pode ser devido ao consumo de dietas à base de carnes, presença de fosfatos de sódio e cálcio na alimentação. $\mathrm{O}$ animal que apresenta
$\mathrm{pH}$ da urina alcalina (acima de 7,5) pode ter esse fato justificado pelo fornecimento de dietas à base de cereais e também pela presença de bicarbonato de cálcio solúvel.

De acordo com França et al. (2011), a quantidade e a origem da proteína influenciam no $\mathrm{pH}$ 
urinário, ou seja, quando há maior eliminação de nitrogênio, isso resultará em pH urinário ácido. Neste experimento, as fontes de proteínas utilizadas na ração dos tratamentos de ração comercial aberta a granel ou fechada foram farinha de vísceras de frango e proteína isolada de suíno representando proteína bruta de, no mínimo, 23,00\%. As fontes de proteínas utilizadas na dieta caseira foram carne e fígado bovino, somando $45,12 \%$ de proteína bruta. Dessa forma, os resultados encontrados confirmam que a quantidade e a qualidade da proteína da dieta caseira e da ração comercial fechada contribuíram para a produção de urina ácida nos cães.

A quantidade de matéria mineral presente na dieta comercial a granel utilizada neste experimento foi de $12,0 \%$, o que representa níveis maiores em comparação com a dieta comercial fechada $(7,50 \%)$ e a deita caseira $(7,04 \%)$, e isso pode justificar a alcalinidade da urina dos cães que foram alimentados com a ração a granel. Da mesma forma, em um estudo utilizando gatos realizado por Yamka et al. (2006), os quais avaliaram 150 dietas secas e úmidas, os autores observaram que o aumento do consumo de cálcio, potássio, sódio e magnésio elevou os níveis de pH na urina. De acordo com
Cappelli et al. (2016), as rações que ficam armazenadas reduzem níveis nutricionais, o que eleva o percentual de minerais em relação aos outros nutrientes e, assim, possibilita a formação de cálculos urinários e císticos.

Ainda, no Brasil as rações industrializadas para cães apresentam, em sua composição, níveis baixos de proteína e níveis altos de cálcio, fósforo e magnésio, em comparação com as rações industrializadas dos Estados Unidos e da Europa. Dessa forma, a composição de algumas rações produzidas no Brasil podem predispor à formação de urina alcalina, o que contribui para a produção de cálculos renais (Carciofi, 2007). Assim, a alimentação natural apresenta-se como alternativa para cães portadores de doenças renais, visando melhorar a condição de vida e reduzir a incidência de novos cálculos renais e também císticos, principalmente após remoção cirúrgica, bem como evitar reincidência de cálculos.

$\mathrm{Na}$ Tab. 4, estão apresentados os resultados da análise química da urina de cães submetidos a diferentes dietas avaliados em dois períodos de cinco dias. Os parâmetros de sangue, bilirrubina e glicose na urina não foram alterados pelas dietas.

Tabela 4. Análise química da urina de cães submetidos a diferentes dietas, avaliados em dois períodos de cinco dias

\begin{tabular}{cccc}
\hline & Dieta caseira & Ração a granel & Ração fechada \\
\hline Sangue $(\mathrm{mg} / \mathrm{dL})$ & Ausente & Ausente & Ausente \\
Corpos cetônicos $(\mathrm{mg} / \mathrm{dL})$ & Ausente & Ausente & Ausente \\
Bilirrubina $(\mathrm{mg} / \mathrm{dL})$ & Ausente & Ausente & Ausente \\
Glicose $(\mathrm{mg} / \mathrm{dL})$ & Ausente & Ausente & Ausente \\
\hline
\end{tabular}

Não foi detectada a presença de sangue, corpos cetônicos, bilirrubina e glicose na urina dos cães de cada dieta durante os períodos de avaliação. No exame de sangue oculto na fita de urinálise, não há distinção entre eritrócitos, hemoglobina e mioglobina, assim, quando houver a presença de sangue oculto, isso deve ser interpretado juntamente com o sobrenadante e a análise do sedimento da urina (Marinho, 2012).

De acordo com Ettinger e Feldman (2014), em condições normais, os corpos cetônicos não estão presentes na urina e a sua presença pode ser causada por uma alimentação com baixo teor de carboidrato e por outras patologias, como cetoacidose diabética. De fato, não houve presença de corpos cetônicos em nenhum dos tratamentos.

No exame para detectar bilirrubina na urina, conforme Dalmolin (2011), é comum encontrar sua presença em pouca ou nenhuma quantidade na urina de cães saudáveis, principalmente em machos. Somente uma parte da bilirrubina conjugada vai para circulação e é filtrada pelos rins, surgindo na urina.

A glicosúria, que é a presença de glicose na urina, normalmente não aparece na urina de cães, pois, por meio do filtrado glomerular, ocorre a reabsorção da glicose nos túbulos proximais. A glicose na urina pode ser causada por doenças 
como Diabetes mellitus e doença renal (Ettinger e Feldman, 2014), sendo a ausência de glicose e dos outros compostos supracitados uma garantia da saúde dos cães submetidos aos tratamentos.

$\mathrm{Na}$ Tab. 5, estão apresentados os resultados da avaliação do escore do pelo dos cães. Cães da dieta caseira e da ração comercial fechada apresentaram o melhor escore de brilho $(\mathrm{P}<0,05)$ em comparação com os cães da ração a granel. Quanto à maciez e à queda de pelo, não houve diferença entre as dietas $(\mathrm{P}>0,05)$.

Tabela 5. Avaliação do escore do pelo de cães submetidos a diferentes dietas, avaliados em dois períodos de cinco dias

\begin{tabular}{cccccc}
\hline Escore do pelo & Dieta caseira & Ração a granel & Ração fechada & Valor de P & CV (\%) \\
\hline Maciez & 3,00 & 2,10 & 3,00 & 0,0911 & 3,1 \\
Brilho & $3,00 \mathrm{a}$ & $1,80 \mathrm{~b}$ & $3,00 \mathrm{a}$ & $0,0441^{*}$ & 8,0 \\
Queda & 3,00 & 2,80 & 2,80 & 0,6342 & 6,1 \\
\hline
\end{tabular}

*Médias seguidas por letras diferentes são diferentes pelo teste de Kruskal-Wallis (5\%).

CV - coeficiente de variação.

Os ácidos graxos essenciais, como o ômega 6, são importantes para a qualidade do pelo, sobretudo o ácido linoleico, que pode ser encontrado em óleos vegetais e gordura de frango; já o ácido araquidônio é encontrado principalmente em gorduras animais, como óleo de peixe e gordura de frango. As fontes de ômega 3 podem ser encontradas em óleos de peixe de águas frias e em algumas algas e também na semente de linhaça. A deficiência dos ácidos graxos essenciais pode resultar em queda de pelo, com aparência seca e opaca (Murray et al., 2015). A ração comercial fechada foi constituída de ômega 6 e 3, a qual contribuiu para a melhor qualidade de pelo, assim como a dieta caseira, que, por possuir ingredientes naturais, teve melhor aproveitamento no pelo. Já a ração comercial a granel, devido a sua exposição de 30 dias ao ambiente, foi deficiente, possivelmente devido a atividades oxidativas, assim resultou em piores escores de qualidade de pelo.

A avaliação do odor fecal foi feita por meio da amostra padrão, ou seja, a ração comercial fechada. $\mathrm{O}$ escore de odor da dieta caseira foi a que mais se aproximou da amostra padrão, apresentando maior resultado $(\mathrm{P}<0,05)$. Já o escore de odor fecal da dieta composta de ração a granel apresentou escore pior que o padrão, tendo menor resultado $(\mathrm{P}<0,05)$. A Tab. 6 mostra a avaliação do escore de odor das fezes dos cães submetidos a diferentes dietas, avaliados por dois períodos de cinco dias.

Tabela 6. Avaliação do escore odor das fezes ${ }^{1}$ de cães submetidos a diferentes dietas, avaliados em dois períodos de cinco dias

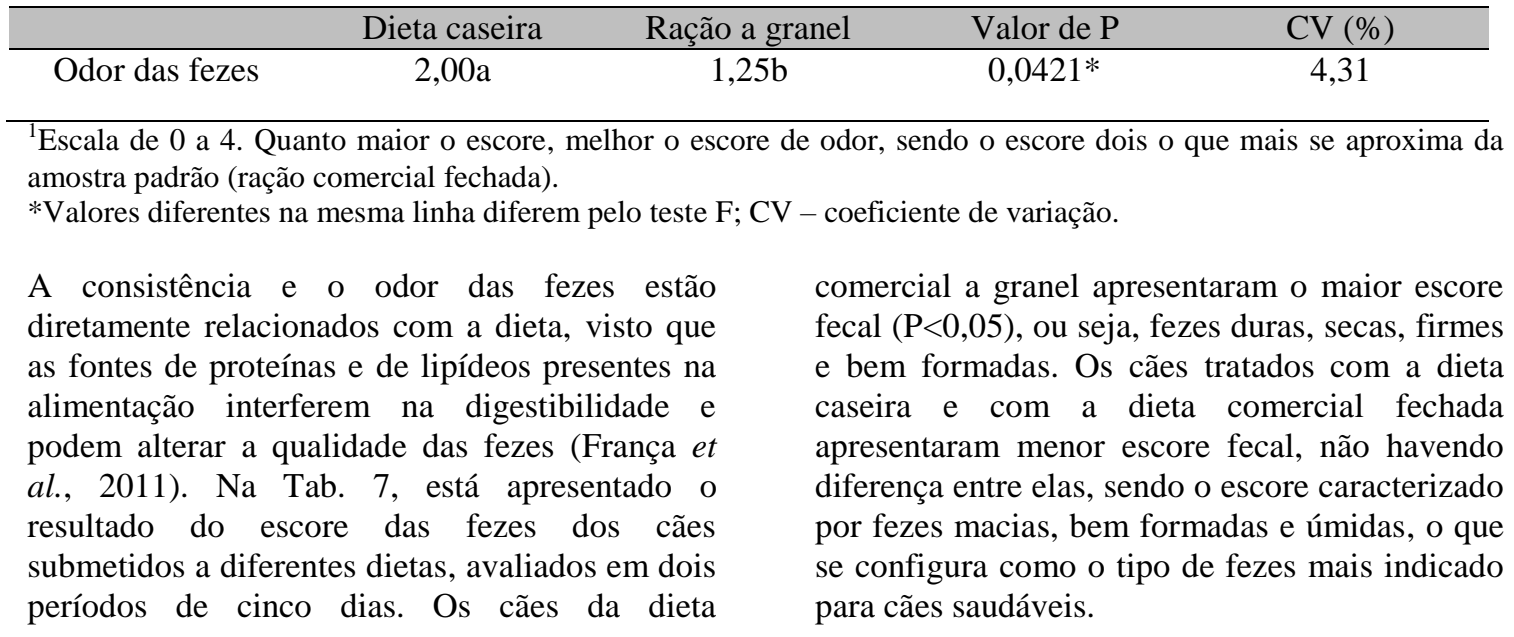


Tabela 7. Escore fecal de cães submetidos a diferentes dietas, avaliados em dois períodos de cinco dias

\begin{tabular}{lccccc} 
& Dieta caseira & Ração a granel & Ração fechada & $\begin{array}{c}\text { Valor de } \\
\text { P }\end{array}$ & $\begin{array}{c}\text { CV } \\
(\%)\end{array}$ \\
\hline Escore fecal & $3,30 \mathrm{~b}$ & $4,60 \mathrm{a}$ & $3,41 \mathrm{~b}$ & $0,0411^{*}$ & 2,3 \\
\hline
\end{tabular}

*Médias seguidas por letras diferentes são diferentes pelo teste de Kruskal-Wallis (5\%).

$\mathrm{CV}$ - coeficiente de variação.

Os cães da alimentação a granel apresentaram resultado de fezes mais secas quando comparados aos outros tratamentos $(\mathrm{P}<0,05)$. Esse achado pode ser justificado pela possível redução na disgestibilidade da ração, ocasionada pelo armazenamento em ambiente. Em uma pesquisa realizada por Carciofi et al. (2006), houve produção de fezes mais secas por cães que ingeriram rações com fontes de proteína menos digestíveis. Fezes muito ressecadas não são desejadas, pois podem levar à retenção fecal, o que pode machucar a mucosa retal do cão, e também podem provocar alterações digestivas (Félix et al., 2009). Médicos veterinários de clínicas devem alertar os tutores de cães quanto ao risco de desenvolvimento de patologias geradas por fezes muito secas, volumosas e duras. Dessa forma, tanto a dieta caseira quanto a ração comercial fechada proporcionaram fezes satisfatórias, compatíveis com a saúde do cão.
A dieta caseira utilizada neste experimento, com média de $73,00 \%$ de umidade, proporcionou melhor escore fecal para os cães. França et al. (2011), em estudo que utilizou uma dieta natural constituída por carne bovina com alta umidade, encontraram melhor escore fecal para cães que receberam a dieta natural em comparação ao escore fecal de cães que receberam dietas enlatadas ricas em proteínas. Assim, a qualidade das fezes é influenciada pela quantidade de água e também pela fonte e quantidade de proteína presente em sua constituição.

$\mathrm{Na}$ Tab. 8, estão apresentados os resultados do escore de volume fecal dos cães submetidos a diferentes dietas, avaliados em dois períodos de cinco dias. Os cães alimentados com a ração a granel apresentaram fezes mais volumosas $(\mathrm{P}<0,05)$ em comparação aos animais dos outros tratamentos.

Tabela 8. Escore do volume fecal de cães submetidos a diferentes dietas, avaliados em dois períodos de cinco dias

\begin{tabular}{cccccc} 
& Dieta caseira & Ração a granel & Ração fechada & Valor de P & CV (\%) \\
\hline Escore & $1,05 \mathrm{~b}$ & $2,00 \mathrm{a}$ & $1,20 \mathrm{~b}$ & $0,0311^{*}$ & 5,0 \\
\hline
\end{tabular}

*Médias seguidas por letras diferentes são diferentes pelo teste de Kruskal-Wallis (5\%).

$\mathrm{CV}$ - coeficiente de variação.

De acordo com Saad e França (2010), a digestibilidade da dieta influencia no volume das fezes, pois quanto maior a digestibilidade do alimento, menor será o volume das fezes. As fezes dos cães da ração a granel apresentaram maior volume fecal possivelmente devido à menor digestibilidade provocada pelo armazenamento inadequado da ração.

Ainda, segundo Felix et al. (2009), proteínas de baixa qualidade e de grande quantidade de fibras na dieta diminuem a digestibilidade, aumentando, assim, o volume fecal. No presente experimento, além de a ração a granel ter apresentado baixa qualidade, ela também apresentou maior nível de matéria fibrosa $(3,00 \%)$ em relação à dieta caseira $(2,89 \%)$, que apresentou, em sua composição, proteína de melhor qualidade e menores níveis de matéria fibrosa, o que contribuiu para menor volume fecal.

$\mathrm{Na}$ Tab. 9, estão representados os resultados da avaliação do consumo voluntário de cães submetidos a diferentes dietas, avaliados em dois períodos de cinco dias. A porcentagem dos cães que apresentaram o consumo voluntário no tempo médio de 10 minutos foi maior na dieta caseira e na ração comercial fechada $(\mathrm{P}<0,05)$, não havendo diferença entre elas; já os cães alimentados com a ração a granel tiveram a menor porcentagem de consumo nesse tempo $(\mathrm{P}<0,05)$. O tempo médio de 20 a 30 minutos teve maior porcentagem nos cães da ração a 
granel $(\mathrm{P}>0,05)$. As outras dietas apresentaram um tempo de consumo das rações inferior $(\mathrm{P}<0,05)$, não havendo diferenças entre elas.

A dieta caseira apresentou energia bruta de $5.290,10 \mathrm{kcal} / \mathrm{kg}$, sendo maior em comparação com a ração comercial fechada, que apresentou $3.881 \mathrm{kcal} / \mathrm{kg}$. Segundo Zanatta (2013), o consumo de alimento é regulado pela quantidade de energia presente na dieta, portanto a ingestão de alimento com alta quantidade energética faz com que o consumo acabe antes de o estômago se encher, pois os teores energéticos sanguíneos são atingidos rapidamente e, com isso, há envio de mensagem para o hipotálamo, o que promove a saciedade. Apesar da alta energia apresentada na dieta caseira, não houve alteração no consumo da dieta, assim não ocorreram sobras de alimentos, possivelmente devido à melhor palatabilidade desse tipo de dieta.

Tabela 9. Avaliação do consumo voluntário de cães submetidos a diferentes dietas, avaliados em dois períodos de cinco dias consecutivos

\begin{tabular}{cccccc}
\hline & \multicolumn{5}{c}{ Cães que tiveram o consumo total da ração (\%) } \\
\hline Tempo médio de & $\begin{array}{c}\text { Dieta } \\
\text { caseira }\end{array}$ & $\begin{array}{c}\text { Ração a } \\
\text { granel }\end{array}$ & $\begin{array}{c}\text { Ração } \\
\text { fechada }\end{array}$ & Valor de P & CV $(\%)$ \\
Até 10 minutos & $85,00 \mathrm{a}$ & $45,00 \mathrm{~b}$ & $80,00 \mathrm{a}$ & $0,0357^{*}$ & 12,9 \\
Até 20 minutos & $10,00 \mathrm{~b}$ & $35,00 \mathrm{a}$ & $15,00 \mathrm{~b}$ & $0,0451^{*}$ & 8,2 \\
Até 30 minutos & $5,00 \mathrm{~b}$ & $20,00 \mathrm{a}$ & $5,00 \mathrm{~b}$ & $0,0310^{*}$ & 7,1 \\
\hline
\end{tabular}

*Médias seguidas por letras diferentes na mesma linha são diferentes pelo teste de Tukey (5\%).

CV - coeficiente de variação.

Os cães preferem alimentos com cheiro e sabor de carne, e as características físicas dos alimentos, como tamanho, formato, dureza, densidade e umidade, interferem na ingestão (Zanatta, 2013). De acordo com Houpt et al. (1978), os cães têm preferência por dietas úmidas a secas, devido ao fato de as úmidas apresentarem maior palatabilidade, e preferem também carne fresca, principalmente carne bovina, por também conferir maior palatabilidade do que os alimentos à base de milho e farelo de soja. A palatabilidade e a umidade presentes na dieta caseira deste experimento contribuiu para o consumo mais rápido. A umidade presente na ração comercial fechada foi semelhante à da ração a granel, porém possivelmente a palatabilidade foi melhor para a ração comercial fechada, o que também contribuiu para o consumo mais rápido.

De acordo com Zanatta (2013), o consumo voluntário é influenciado pelo comportamento, pela contaminação dos alimentos e pelas características socias, como a presença de animais dominantes, a facilidade de conviver com outros animais, bem como as características individuais. Esses fatores também podem ser explicados para o resultado do consumo voluntário da ração a granel desta pesquisa, em que a exposição da ração ao ambiente pode ter contribuído para a diminuição da palatabilidade.
Os animais utilizados neste experimento apresentavam comportamentos individuais de dispersão ou hiperatividade quando havia movimentação, presença de insetos, barulhos, latidos dos outros cães que participavam do experimento e presença de outras pessoas. Apesar dessas individualidades, o consumo voluntário foi mais rápido para a dieta caseira do que para a ração a granel. Ao perceberem que a alimentação seria oferecida, os cães já se movimentavam e, ao sentirem o cheiro da dieta caseira, mostravam-se agitados e ansiosos.

\section{CONCLUSÃO}

Foi possível concluir que os efeitos observados em cães que receberam a alimentação caseira são muito similares aos que receberam a ração comercial fechada tipo premium, sendo a utilização da ração a granel tipo premium não recomendada, uma vez que prejudicou os cães em diversos aspectos analisados no experimento.

\section{REFERÊNCIAS}

AQUINO, A.A.; ALVES, M.P.; SANTOS, J.P.F. et al. Efeitos do extrato de parede de levedura em dieta seca sobre a microbiologia, ácidos graxos de cadeia curta e redução do odor das fezes de gatos adultos. Ciênc. Anim. Bras., v.13, p.479-486, 2012. 
BELTRAME， O.C.; LOCATELLI-DITTRICH， R.; LASKOSKI, L.M. et al. Hemoglobina glicada e frutosamina em cães com diabetes mellitus. Ciênc. Anim. Bras., v.16, p.548-552, 2015.

BOTELHO, G.G.; BOTELHO, C.M.; BOTELHO, C.F.M.; PAZ, J.G. Relação proteína/creatinina urinária (PU/CrU) em bovinos leiteiros. Rev. Bras. Med. Vet., v.34, p.121-126, 2012.

BUFF, P.R.; CARTER, R.A.; BAUER, J.E.; KERSEY, J.H. Natural pet food: a review of natural diets and their impact on canine and feline physiology. J. Anim. Sci., v.92, p.3781-3791, 2014.

CAPPELLI, S.; PATRYCIA. L.; FREITAS, C.P. et al. Avaliação química e microbiológica das rações secaspara cães e gatos adultos comercializadas a granel. Rev. Bras. Hig. Sanit. Anim., v.10, p.90-102, 2016.

CARCIOFI, A.C. Métodos para estudo das respostas metabólicas de cães e gatos a diferentes alimentos. Rev. Bras. Zootec., v.36, p.235-249, 2007.

CARCIOFI, A.C.; PONTIERI, R.; FERREIRA, C.F.; PRADA, F. Avaliação de dietas com diferentes fontes protéicas para cães adultos. Rev. Bras. Zootec., v.35, p.754-760, 2006.

DALMOLIN, M.L. A urinálise no diagnóstico das doenças renais. Porto Alegre: UFRGS, 2011. Disponível em: <http://www.ufrgs.br/restrito/pdf/magnus_urinalise.pd f>. Acesso em: 15 jul. 2016.

ETTINGER, S.J.; FELDMAN, E.C. Tratado de medicina interna veterinária: doença do cão e do gato. 5.ed. Rio de Janeiro: Guanabara Koogan, 2014, v.2, 2256p.

FÉLIX, A.P. Avaliação nutricional de derivados proteicos de soja para cães. Curitiba: Universidade Federal do Paraná, 2011. 188p.

FÉLIX, A.P.; SÁ-FORTES, C.; SILVA, A. et al. Digestibilidade de uma dieta caseira e dois alimentos comerciais, econômico e super-prêmio, para cães. Arch. Vet. Sci., v.14, p.25-30, 2009.

FRANÇA, J.; SAAD, F.M.O.B.; SAAD, C.E.P. et al. Avaliação de ingredientes convencionais e alternativos em rações de cães e gatos. Rev. Bras. Zootec., v.40, p.222-231, 2011.

HOUPT, K.A.; HINTZ, H.F.; SHEPHERD, P. The role of olfaction in canine food preferences. Chem. Senses, v.3, p.281-290, 1978.

LAMOUNIER, R.N.; GUIMARÃES, D.B.; CONSOLI, M.L. Manual de contagem de carboidratos. Belo Horizonte: Centro de Diabetes de Belo Horizonte, 2010. 28p.
MARINHO, T.R. Avaliação da proteinúria como marcador de lesão/doença renal subclínica em cães. 2012. 65f. Dissertação (Mestrado em Ciências Veterinárias) - Universidade de Trás-os-Montes e Alto Douro, Vila Real, POR.

MENDES, J.V.; PIRES, P.G.S.; TEIXEIRA, L. et al. Avaliação de alimentos secos industrializados para cães e gatos expostos ao ambiente. Enc. Biosfera, v.10, p.306, 2014

MORAIS, L.F. A máxima "consulte um especialista" nunca fez tanto sentido. Rev. Cães Gatos Vet. Food, n.195, p.34-35, 2015.

MURRAY, M.; EDWARDS, M.A.; ABERCROMBIE, B. et al. Poor health is associated with use of anthropogenic resources in an urban carnivore. Proc. R. Soc. Biol. Sci., v.282, p.1-8, 2015.

NUTRIENT requirements of dogs and cats. Washington: Nacional Academy of Science, 2006. $424 \mathrm{p}$.

R DEVELOPMENT core team: a language and environment for statistical computing. Version 3.4.4. Vienna: R Foundation for Statistical Computing, 2016.

ROCHA, M.A. Biotecnologia na nutrição de cães e gatos. Rev. Bras. Zootec., v.37, p.42-48, 2008.

SAAD, F.M.O.B.; FRANÇA, J. Alimentação natural para cães e gatos. Rev. Bras. Zootec., v.39, p.52-59, 2010.

SILVA, D.J.; QUEIROZ, A.C. Análise de alimentos: métodos químicos e biológicos. Viçosa, MG: UFV. 2002. 235p.

TSUDA, K.; KIKKAWA, Y.; YONEKAWA, H. et al. Extensive interbreeding occurred among multiple matriarchal ancestors during the domestication of dogs: evidence from inter- and intraspecies polymorphisms in the D-loop region of mitochondrial DNA between dogs and wolves. Genes Genet. Syst., v.72, p.229-238, 1997.

YAMKA, R.M.; FRIESEN, K.G.; SCHAKENRAAD, $\mathrm{H}$. The prediction of urine $\mathrm{pH}$ using dietary cations and anions in cats fed dry and wet foods. J. Appl. Res. Vet. Med., v.4, p.58-66, 2006.

ZANATTA, C.P. Determinação de protocolo para avaliação da preferência alimentar em cães. Curitiba: UFP, 2013.

ZANI, A.O câmbio favoreceu as exportações, mas encareceu insumos. Bol. Inf. Setor Aliment. Anim., 2015. Disponível em: <http://sindiracoes.org.br/ wpcontent/uploads/2015/12/boletim_informativo_do_ setor_de_alimentacao_animal_dez2015_online.pdf $>$. Acessado em: 05 maio 2016 